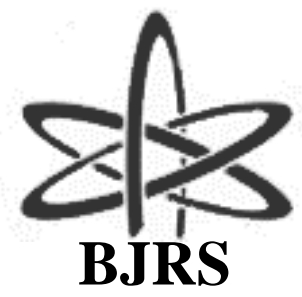
BRAZILIAN JOURNAL
$\mathrm{OF}$
RADIATION SCIENCES
09-01 (2021) 01-26

\title{
Comparação entre métodos de medição da camada semi-redutora em radiologia
}

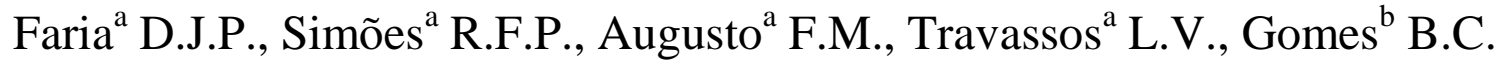 \\ ${ }^{a}$ Instituto Nacional de Câncer José Alencar Gomes da Silva (INCA) / Seção de Física Médica - Radiologia, 20230-130, \\ Rio de Janeiro, RJ, Brasil \\ ${ }^{b}$ Pró-Sigma Serviços de Proteção Radiológica e Física Médica, 20230-900, Rio de Janeiro, RJ, Brasil \\ denyelfaria@gmail.com
}

\section{RESUMO}

A Camada Semi-Redutora (CSR) é um parâmetro usado no Controle de Qualidade (CQ), para avaliar a qualidade do feixe de raios X. A CSR pode ser medido através da medição da atenuação do feixe primário de raios $\mathrm{X}$ utilizando placas de espessura conhecida de $99 \%$ de pureza de alumínio (M1) ou ajustando a melhor curva (M2) ou por dosímetro multiuso (detector de estado sólido) (M3). O M1 desgasta mais o tubo de raios X e requer muito tempo de aquisição e processamento de dados, porém é o método padrão recomendado pelo Manual de Segurança Radiológica. O último método (M3) é prático e não é influenciado pela mudança abrupta do espectro de transmissão dos raios $X$, pois não requer o uso de placas de alumínio. Os equipamentos utilizados para medir a radiação foram os dosímetros NOMEX, Cobia Smart, UNFORS XI e Câmara de Ionização Radcal. As fontes utilizadas foram: raios $\mathrm{X}$ móveis, raios $\mathrm{X}$ fixo e dois mamógrafos diferentes. Os resultados mostraram que a maior variação percentual foi de 15,6\% entre M1 e M3 para mamógrafos com filtro/alvo W/Rh. Para os raios $X$ convencionais, cuja combinação alvo/filtro é W/Al, a maior variação foi de 3,3\% entre M1 e M3. Assim, os resultados mostram que a estimativa de CSR pode ser realizada por qualquer um dos três métodos ou equipamentos, desde que a combinação alvo/filtro seja W/Al. Para combinações alvo/filtro diferentes de W/Al, as variações percentuais aumentam consideravelmente e não recomendamos o uso de M1 para este tipo de medição.

Palavras-chave: Camada Semi Redutora, Placas de Alumínio, Medida Manual, Medida Automática. 


\begin{abstract}
The Half Value Layer (HVL) is a parameter used in Quality Control (QC), to evaluate the X-ray beam quality. The HVL can be measured through the $\mathrm{X}$-ray primary beam attenuation measurement using knew thickness slabs of $99 \%$ purity aluminum (M1) or by adjusting the best curve (M2) or by multipurpose dosimeter (solid state detector) (M3). The M1 wears out the $\mathrm{X}$-ray tube more and requires a long time of data acquisition and processing, however, it is the standard recommended method for the Radiological Safety Manual. The last one method (M3) is practical, and is not influenced by the abrupt change in the X-ray transmission spectrum, as it does not require the use of aluminum plates. The equipment used to measure radiation were the NOMEX Dosemeter, Cobia Smart, UNFORS XI and Radcal Ionization Chamber. The sources used were: mobile X-ray, fixed $X$-rays and two different mammographs. The results showed that the biggest difference was $15.6 \%$ between M1 and M3 for mammography equipment with a filter/target W/Rh. For conventional $X$-rays, that the target/filter combination is W/Al, the biggest difference was 3.3\% between M1 and M3. Thus, the results show that the HVL estimate can be performed by any of the three methods or equipment, as long as the target/filter combination is W/Al. For filter/target combination other than W/Al the percentage differences increase considerably and we do not recommend the use of M1 for this type of measurement.
\end{abstract}

Keywords: Half Value Layer, Aluminum Slabs, Manual Measurement, Automatic Measurement. 


\section{INTRODUÇÃO}

A Camada Semi Redutora (CSR), igualmente conhecida como HVL (do inglês, Half-Value Layer) é utilizada na radiologia para descrever a qualidade dos feixes de raios X. Essa é reconhecida pela descrição da capacidade de penetrabilidade do feixe de raios X. A CSR é definida como a espessura de material absorvedor necessária para reduzir a intensidade do feixe de radiação à $50 \%$ da intensidade original ${ }^{1}$ sob condições de boa geometria ${ }^{2}$ [1-3]. Uma avaliação da qualidade do feixe de radiação pode ser realizada diretamente através do valor de CSR [1,3,4]. Esta avaliação é muito valiosa na radiologia, visto que é um indicador da influência dos fótons de baixa energia que não atravessam o paciente e nem atingem o receptor de imagem, desta forma incrementam a dose de entrada na pele no paciente sem agregar qualquer benefício à qualidade da imagem diagnóstica [4], por outro lado, um feixe muito endurecido, ou seja, muito filtrado, oferece baixa capacidade de estabelecimento do contraste adequado. A recomendação da Agência Internacional de Energia Atômica (AIEA) na mamografia, por exemplo, [5] é de que o uso do equipamento seja interrompido e que uma ação corretiva seja aplicada imediatamente tanto no caso da observação da CSR fora dos limites de tolerância aceitáveis ou recomendados.

Um método consolidado para avaliar a qualidade do feixe de radiação é a análise da distribuição espectral de energia. Entretanto, medições do espectro energético dos equipamentos utilizados na radiologia só é possível com o uso de um espectrômetro de raios $\mathrm{X}$ e este instrumento não faz parte do parque tecnológico usualmente encontrado nos hospitais. Esta tecnologia de detecção da radiação é capaz de identificar a intensidade do feixe em função do comprimento de onda [6]. Uma segunda opção de avaliação da qualidade do feixe de radiação é a partir da determinação da energia efetiva do feixe, que corresponde ao valor predominante de energia na distribuição espectral. Esse valor é aproximadamente $30 \%$ a $50 \%$ do pico energético que pode ser considerado como a energia de um feixe monoenergético de fótons capazes de produzir o mesmo efeito do feixe continuo [1]. Energia efetiva é relacionada à CSR e também pode ser obtida através de modelos matemáticos a

1 Intensidade do feixe de radiação sem nenhum filtro adicional.

2 Conhecido como condição de feixe estreito, condição essa que garante que apenas alcance o detector fótons primários transmitidos pelos materiais atenuadores [1] 
partir do conhecimento prévio do coeficiente de atenuação mássico ou do coeficiente de atenuação linear [1-3].

A maneira tradicional de obtenção da CSR é através da medição da variação do kerma no ar devido a atenuação do feixe primário de raios $\mathrm{X}$ por interposição de atenuadores com diferentes espessuras [4]. Esse método se baseia na determinação da intensidade do feixe de raios X para diferentes espessuras (previamente conhecidas) de placas de alumínio com pureza acima de 99\%, enquanto outros parâmetros de exposição como, tensão e produto corrente-tempo permanecem constantes [1-4]. A espessura de alumínio (Al) destes filtros que é capaz de reduzir a intensidade do feixe de raios $X$ à metade do valor da intensidade inicial (ou intensidade original ${ }^{1}$ ) indica a CSR.

Atualmente, estimativa da CSR pode ser realizada automaticamente (CSR rápida) ${ }^{3}$ em medidores modernos baseados em detectores do estado sólido, que através de um modelo matemático (polinômio de transferência) $[10,15]$ a partir da Filtração Total (FT) do feixe ${ }^{4}$, ou combinação de sinais de múltiplos detectores e filtros internos, calcula a CSR [7-10]. A relação é obtida após o equipamento ser calibrado individualmente em uma faixa de valores de referência de CSR $[10,11]$. A relação obtida entre CSR e FT dá origem a um gráfico conhecido como diagrama de qualidade [12-14], de onde o modelo matemático é determinado, e permite não apenas a conversão de FT em CSR, mas de CSR em FT. É importante ressaltar que essa relação entre FT e CSR varia com a tensão aplicada no tubo de raios X, e com o material e ângulo do alvo (anodo) [13, 15]. Geralmente, esse diagrama de qualidade é obtido para um tubo de raios $X$ com alvo de Tungstênio e $14^{\circ}$ de inclinação do anodo, tipicamente utilizados em radiologia diagnóstica [15]. Cada fabricante de detectores desenvolve e aplica no software de seus dispositivos os detalhes desse modelo.

Cada método de medição de CSR tem seus pontos positivos e negativos. O método convencional que utiliza várias exposições, por exemplo, é um método que impõe maior desgaste do tubo de raios $\mathrm{X}$, maior tempo para aquisição e processamento dos dados, uma vez que o procedimento consiste de uma série de exposições com a mesma programação de intensidade do feixe e possui limitações inerentes aos desvios de repetibilidade da taxa de kerma de alguns

3 Conhecido em inglês como Quick-HVL.

4 Em radiologia diagnóstica, refere-se a filtro capazes de remover fótons de baixa energia desnecessário para a formação da imagem diagnóstica de interesse, reduzindo a exposição à radiação do paciente. A NCRP determina valores mínimos de filtração total [1]. 
aparelhos de raios X [4]. Entretanto, esse método é adotado como o padrão e indicado pelo Manual de Segurança Radiológica, editado pela própria Agência Nacional de Vigilância Sanitária ANVISA [16], guia europeu para garantia de qualidade em câncer de mama [17], referência internacionalmente reconhecida em CQ de mamógrafos, além de outras [5, 18-23]. O método que utiliza o sensor do estado sólido é prático, porém, pode se tornar inexato ${ }^{5}$ dependendo das características do tubo de raios $\mathrm{X}$ analisado, isso porque o equipamento sob investigação deve ser de parâmetros técnicos equivalentes e operado sob as mesmas condições do tubo de referência, a partir do qual o diagrama de qualidade foi obtido [14, 15].

A possibilidade de se utilizar duas metodologias para estimar um mesmo parâmetro (CSR), motivou a realização dessa pesquisa. O objetivo deste trabalho é conhecer o quanto o valor da CSR obtido por detectores do estado sólido desvia do valor obtido pelo método convencional adotado pelos manuais de regulamentação nacional e internacional, por conseguinte, será possível discutir a precisão ${ }^{6}$ dos valores obtidos por cada metodologia e, verificar a hipótese da ocorrência de uma variação percentual entre os valores absolutos de CSR entre os métodos e por fim, definir o método mais adequado para essa avaliação.

\section{MATERIAIS E MÉTODOS}

A coleta de dados foi realizada nas unidades do Instituto Nacional de Câncer José Alencar Gomes da Silva (INCA). Os equipamentos utilizados para medição foram: NOMEX Dosemeter, modelo T11050, fabricado pela PTW calibrado em 12 de julho de 2019; Cobia Smart R/F, versão 2.1, fabricado pela RTI Electronics calibrado em 16 de janeiro de 2018, UNFORS modelo XI calibrado em 12 de julho de 2019, e a Câmara de Ionização de $60 \mathrm{~cm}^{3}$ de volume sensível conectada ao eletrômetro de modelo 2026C, fabricado pela RadcalCorporation. Os equipamentos testados foram: um aparelho de raios X convencional fixo (RX-F) modelo Polymat Plus S fabricado pela

5 Inexato é um algo que não é exato, sendo a exatidão definida como o grau de concordância dos resultados com o "valor verdadeiro" ou o valor de referência a ser determinado [24].

6 A precisão é definida como o grau de concordância dos resultados entre si, normalmente expresso como o desvio padrão em relação à média [24], ou múltiplos desse desvio padrão, ou a metade de um intervalo correspondente a um nível de confiança estabelecido, e que caracteriza a dispersão dos valores [25]. Metade do nível de confiança estabelecido é conhecido como incerteza e pode ser obtido a partir de informações confiáveis como especificações do fabricante, dados fornecidos em certificados de calibração e outros certificados, dados de medição prévia, etc. [25]. 
SIEMENS com filtração inerente de $2 \mathrm{~mm} \mathrm{Al}$ e filtração adicional de $1,5 \mathrm{~mm} \mathrm{Al}$, dois aparelhos de raios X móveis (RX-M) modelo MobileArtEvolution fabricado pela SHIMADZU, com filtração inerente de 1,5 mm Al e filtração adicional de 1,0 mm Al, e dois mamógrafos (MM), sendo o MAMMOMAT modelo 3000 Nova, fabricado pela SIEMENS com alvo de molibdênio e filtros de molibdênio ou ródio, possui filtração inerente de $0,8 \mathrm{~mm}$ Be e, o mamógrafo com tomossíntese, modelo FFDM-SD, fabricado pela HOLOGIC com alvo de tungstênio e, filtros de ródio ou prata apresenta filtração inerente de $0,5 \mathrm{~mm}$ Be. O RX-F e os RX-M possuem alvo de tungstênio e filtro de alumínio. Todos os equipamentos citados apresentavam os testes de controle de qualidade atualizados e em conformidade com as normas vigente e as definições especificado pelo fabricante. A Tabela 1 apresenta a relação entre os tipos de equipamentos utilizados, alvos e filtros.

Tabela 1: Marca, modelo e Alvo-Filtro dos tipos de fontes de radiação utilizadas no estudo.

\begin{tabular}{cccc}
\hline Tipo & Marca & Modelo & Alvo/Filtro \\
\hline Raios X Fixo (RX-F) & SIEMENS & Polymat Plus S & W/Al \\
Raios X Móvel (RX-M) & SHIMADZU & MobileArtEvolution & W/Al \\
Mamógrafo (MM-1) & MAMMOMATE & 3000 Nova & Mo/Rh-Mo/Mo \\
Tomossíntese (MM-2) & HOLOGIC & FFDM-SD & W/Rh-W/Ag \\
\hline
\end{tabular}

\subsection{Arranjo experimental e parâmetros utilizados}

A Figura 1 apresenta o arranjo experimental utilizado para obtenção da CSR em um equipamento de RX-F (A) e um equipamento de MM (B). 

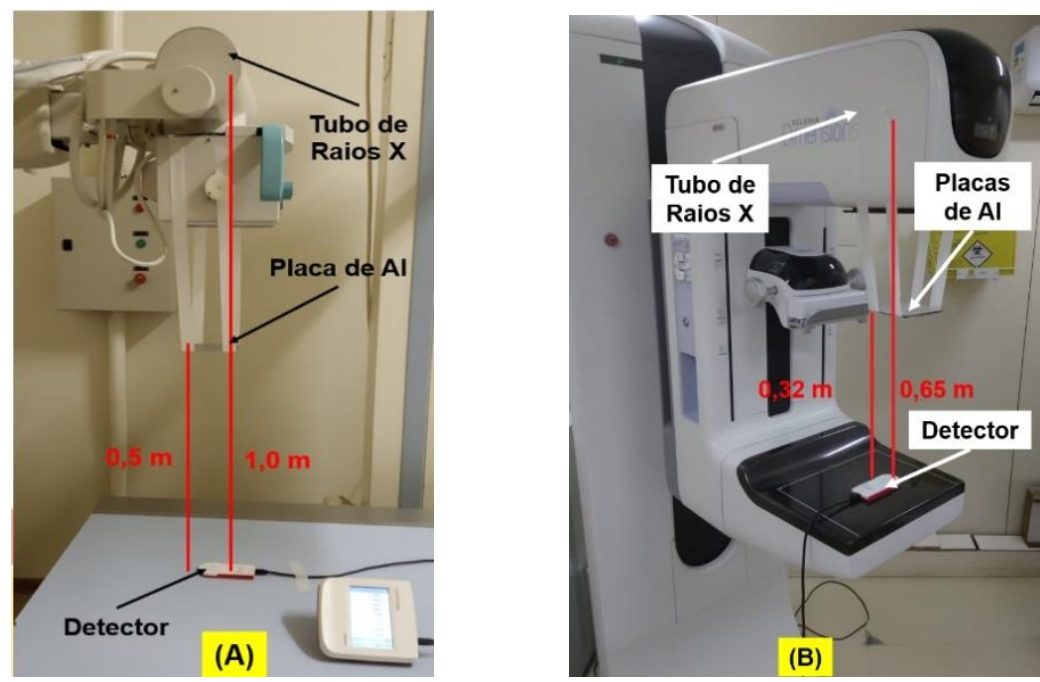

Figura 1: Arranjo experimental apresentando o tubo de raios $X$, a posição das placas de Al e $O$ detector. Em (A) equipamento de raios X fixo e em (B) equipamento de mamografia.

Em RX-F e RX-M o detector sobre a mesa, foi posicionado a 1,0 $\mathrm{m}$ do ponto focal e as placas de $\mathrm{Al}$ foram posicionadas a meia distância $(0,5 \mathrm{~m})$ entre o ponto focal e o detector para evitar a influência do espalhamento na medição. Os parâmetros de exposição foram: tensão de $80 \mathrm{kVp}$ e produto corrente-tempo de $50 \mathrm{mAs}$, com o detector de $0,16 \mathrm{x} 0,15 \mathrm{~m}^{2}$ centralizado no campo de radiação de $0,30 \times 0,30 \mathrm{~m}^{2}$.

Em MM os parâmetros de exposição foram: tensão de $28 \mathrm{kVp}$ e produto corrente-tempo de $50 \mathrm{mAs}$, com o detector posicionado a $0,65 \mathrm{~m}$ do ponto focal e as placas de Al posicionadas a meia distância $(0,32 \mathrm{~m})$ entre o ponto focal e o detector sem o uso da bandeja de compressão.

Em ambos os testes, uma avaliação da correspondência do campo luminoso com o campo de radiação foi feita antes do posicionamento dos detectores.

\subsection{Método de medição tradicional}

Seguindo o arranjo experimental apresentado na Figura 1 foram feitas três exposições sem material atenuador e os valores foram anotados. Depois novas exposições foram realizadas acrescentado placas de Al com $99 \%$ de pureza a meia distância entre o detector e o ponto focal até obter uma leitura de exposição inferior à metade do valor inicial [15]. As espessuras de placa de alumínio variam de 0,5 a 5,0 mm (para RX-F e RX-M) e 0,1 a 3,0 mm (para MM) com incerteza na 
espessura de $\pm 5 \%$. Os erros associados as leituras de exposição da Câmara de Ionização são de $\pm 4 \%$ do valor medido [26]. Para o NOMEX, o erro associado é de $\pm 3,5 \%$ para RX-F e RX-M, e de $\pm 2,5 \%$ para MM [7]. Para Cobia Smart e Unfors, o erro associado é $\pm 5 \%$ [9].

A CSR foi obtida através da interpolação entre o valor imediatamente superior e o valor imediatamente inferior ao valor correspondente a metade do valor inicial como apresentado pela Eq. $1[15,16,20-22]$ :

$$
\operatorname{CSR}=\frac{x_{0} \ln \left(2 \frac{y_{1}}{a}\right)-x_{1} \ln \left(2 \frac{y_{0}}{a}\right)}{\ln \left(\frac{y_{1}}{y_{0}}\right)}
$$

Onde:

$\left(x_{1}, y_{1}\right) e\left(x_{0}, y_{0}\right)$ são respectivamente os pontos imediatamente superior e inferior ao ponto de valor correspondente a metade do valor inicial $a$.

$y_{l}$ é a leitura de exposição imediatamente superior a $a / 2$

$x_{l}$ é a espessura de alumínio correspondente a leitura $y_{1}$

$y_{0}$ é a leitura de exposição imediatamente inferior a $a / 2$

$x_{0}$ é a espessura de alumínio correspondente a leitura $y_{0}$

O erro associado a essa estimativa foi obtido através da propagação de erros, Eq. 2.

$|\Delta C S R|=\left[\left|\ln \left(2 \frac{y_{1}}{a}\right)\right| \cdot\left|\Delta x_{0}\right|+\left|\ln \left(2 \frac{y_{0}}{a}\right)\right| \cdot\left|\Delta x_{1}\right|+\left|\frac{\left(x_{0}-C S R\right)}{y_{1}}\right| \cdot\left|\Delta y_{1}\right|+\left|\frac{\left(C S R-x_{1}\right)}{y_{0}}\right| \cdot\left|\Delta y_{0}\right|+\left|\frac{\left(x_{1}-x_{0}\right)}{a}\right| \cdot|\Delta a|\right] \cdot\left|\frac{1}{\ln \left(\frac{y_{1}}{y_{0}}\right)}\right|$

Onde:

$\Delta y_{1}$ é o erro associado a leitura de exposição imediatamente superior a $a / 2$

$\Delta x_{1}$ é o erro associado a espessura de alumínio correspondente a leitura $y_{1}$

$\Delta y_{0}$ é o erro associado a leitura de exposição imediatamente inferior a $a / 2$

$\Delta x_{0}$ é o erro associado a espessura de alumínio correspondente a leitura $y_{0}$

$\Delta a$ é o erro associado a leitura de exposição sem material atenuador interposto no feixe. 
Foi feita uma análise para o caso especial em que vários pontos de medida (mais que 5) foram ajustados por uma linha de tendência para obtermos a melhor equação que represente a relação entre exposição e filtração. Para esse caso, a CSR é obtida pela Eq. 3.

$$
C S R=\frac{-\ln \left(\frac{a}{2} \cdot \frac{1}{a^{\prime}}\right)}{R_{0}}
$$

Onde:

$a$ é o valor de exposição obtido sem material atenuador interposto no feixe de radiação.

$a^{\prime}$ é a constante obtida pelo ajuste da curva, equivalente a exposição sem material atenuador interposto no feixe de radiação.

$R_{0}$ é a constante de decaimento obtido pelo ajuste da curva.

Observe que se o ajuste da curva for perfeito $(\mathrm{R}=1), a=a^{\prime}$ e CSR estimada pela Eq. 3 é igual a CSR estimada pela Eq. 1.

O erro associado a essa estimativa foi obtida através da Eq. 4.

$$
|\Delta C S R|=\left[\left|\frac{\Delta a}{a}\right|+\left|\frac{\Delta a^{\prime}}{a^{\prime}}\right|+\left|C S R \cdot \Delta R_{0}\right|\right] \cdot \frac{1}{R_{0}}
$$

Onde:

$\Delta a$ é o erro associado a leitura de exposição sem material atenuador interposto no feixe.

$\Delta a^{\prime}$ é o erro associado ao valor de $a^{\prime}$ obtido no programa de construção de gráfico.

$\Delta R_{0}$ é o erro associado ao valor de $R_{0}$ obtido no programa de construção de gráfico.

Resultados nesse trabalho associado a CSR obtida pela Eq. 1 é representado por M1 (metodologia 1) e os resultados obtidos pela Eq. 3 é representado por M2 (metodologia 2). Resultados de CSR obtidos pelo método automático, seção 2.3, é representado por M3 (metodologia 3). 


\subsection{Método de medição automático}

Os equipamentos para esse tipo de medição apresentam vários filtros e detectores internos, e capacidade de medição de vários parâmetros em apenas uma exposição. O Cobia Smart por exemplo, possui 4 detectores circulares (D1, D2, D3 e D4) conectados a eletrômetros separados [8]. Quando exposto a um feixe de radiação, a combinação de sinais gerados nesses detectores devido aos diferentes filtros permite calcular com precisão a tensão do tubo [8]. O detector D3, posicionado no centro da cruz, no meio da área do detector é projetado para medir dose. Demais medidas, FT e CSR são estimadas com base nesses sinais. Determinação de FT no range de radiologia é feita com base em uma relação já conhecida entre tensão e FT [6, 8]. Conhecendo-se a tensão e a FT obtém a CSR, a tensão utilizada neste trabalho foram $28 \mathrm{kVp}$ para os mamógrafos e $80 \mathrm{kVp}$ para os equipamentos de raios $\mathrm{X}$ convencionais.

Após determinar o valor de FT, o próximo passo é estimar a CSR. A estimativa da CSR é realizada automaticamente através de um modelo matemático polinomial com critérios de condições de contorno como tensão, ângulo do alvo, material do alvo e material do filtro que são compilados em um software. Para estimar a CSR automaticamente cada fabricante imputa em seus diferentes modelos de equipamentos seus próprios softwares e consequentemente distintos modelos matemáticos cujas condições de contorno não são parametrizadas entre si. Independentemente do modelo matemático adotado pelos fabricantes, toda estimativa de CSR obtida automaticamente precede de um processo de pré calibração em fábrica, onde a FT e tensão são ajustados com base na CSR obtida de forma manual em condições de laboratório e rastreabilidade adequadas, e depois esses dados da pré calibração, FT e tensão, são usados para se obter a CSR automaticamente na rotina de uso do medidor multiparâmetro. Um gráfico que apresenta a relação entre tensão, TF e CSR é conhecido como diagrama de qualidade $[13,15]$. A Figura 2 apresenta um diagrama dessa metodologia de medição de CSR. A incerteza associada à medição é de $\pm 0,25 \mathrm{~mm} \mathrm{Al}$ para RX-F e RX-M e, $\pm 0,01 \mathrm{~mm} \mathrm{Al} \mathrm{para} \mathrm{MM} \mathrm{para} \mathrm{o} \mathrm{NOMEX.} \mathrm{Para} \mathrm{o} \mathrm{Cobia} \mathrm{Smart,} \pm 10 \%$ ou $\pm 0,2 \mathrm{~mm} \mathrm{Al} \mathrm{e}$ para UNFORS, $\pm 10 \%$ ou $\pm 0,3 \mathrm{~mm} \mathrm{Al}$, ambos para RX-F e RX-M. Lembrando que o Cobia Smart e UNFORS, não foram utilizados para medida em MM. 


\section{ESTIMATIVA DE FT E CSR}

UMA EXPOSIÇÃO

DETECTORES E FILTROS

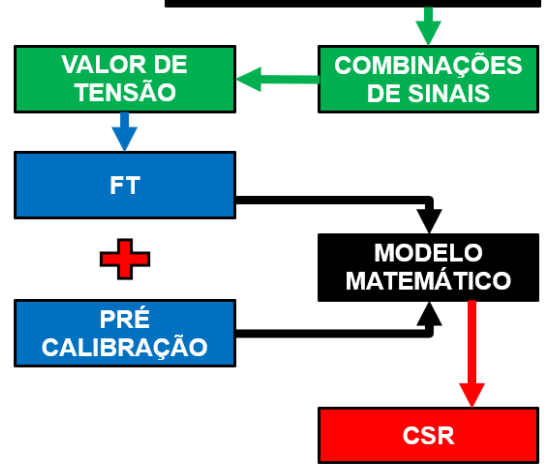

Figura 2: Diagrama do processo de estimativa de CSR por detector de estado sólido.

\section{RESULTADOS E DISCUSSÃO}

A Tabela 2 apresenta os fatores de calibração $\left(\mathrm{N}_{\mathrm{k}}\right)$ para os três detectores do estado sólido utilizados nesse trabalho, aplicados para tensão, kerma no ar e CSR. Fatores obtidos para NOMEX e UNFORS em 12 de julho de 2019 no Instituto Nacional de Câncer José Alencar Gomes da Silva (INCa), foram obtidos através de uma calibração cruzada com o Cobia Smart, calibrado em 16 de janeiro de 2018 em laboratório devidamente homologado na cadeia de rastreabilidade metrológica.

Tabela 2: Fatores de Calibração (Nk) aplicado à Tensão, Kerma no ar e CSR para os três detectores de estado sólido utilizado no trabalho.

\begin{tabular}{|c|c|c|c|c|c|c|c|c|c|c|}
\hline \multirow{2}{*}{ Q Feixe } & \multirow{2}{*}{$\begin{array}{c}\text { Tensão } \\
(\mathbf{k V})\end{array}$} & \multicolumn{3}{|c|}{ Nk [Tensão] } & \multicolumn{3}{|c|}{ Nk [Kerma] } & \multicolumn{3}{|c|}{ Nk [HVL] } \\
\hline & & Cobia & Nomex & Unfors & Cobia & Nomex & Unfors & Cobia & Nomex & Unfors \\
\hline Medido & 50 & 0,9700 & 0,9541 & 0,9607 & 1,0340 & 1,0362 & 1,0516 & 1,0880 & 1,0767 & 0,9779 \\
\hline Int.* & 60 & 0,9815 & 0,9651 & 0,9688 & 1,0310 & 1,0319 & 1,0395 & 1,0520 & 1,0405 & 0,9654 \\
\hline Medido & 70 & 0,9930 & 0,9760 & 0,9768 & 1,0280 & 1,0277 & 1,0273 & 1,0160 & 1,0044 & 0,9528 \\
\hline Int.* & 80 & 1,0025 & 0,9879 & 0,9898 & 1,0470 & 1,0450 & 1,0426 & 1,0219 & 1,0050 & 0,9787 \\
\hline Medido & 90 & 1,0120 & 0,9999 & 1,0027 & 1,0660 & 1,0623 & 1,0579 & 1,0278 & 1,0056 & 1,0046 \\
\hline
\end{tabular}

*Interpolação. 
A Tabela 3 apresenta os resultados da estimativa da CSR usando o Cobia Smart e UnforsXI. A primeira coluna refere-se aos aparelhos de raios $\mathrm{X}$, sendo $\mathrm{RX}-\mathrm{F}$ FF o aparelho de raios $\mathrm{X}$ fixo operado com o foco fino (FF), RX-F FG o aparelho de raios $\mathrm{X}$ fixo operado com o foco grosso (FG), RX-M 1 o aparelho de raios X móvel 1 e RX-M 2 o aparelho de raios X móvel 2 (ambos com foco único). As siglas M1, M2 e M3 são as metodologias de medição como definido no final da seção 2.2. A sigla VP significa Variação Percentual. Na tabela 3 VP M1\&M2, é a variação percentual de M2 com respeito a M1, e VP M1\&M3, é a variação percentual de M3 com respeito a M1. O resultado para a Câmara de Ionização (CI) e o NOMEX são apresentados na Tabela 4.

Tabela 3: Resultado de CSR medidas com o Cobia Smart e UNFORS para as três metodologias (M1, M2 e M3) e variação percentual entre as metodologias M1 \& M2 e M1 \& M3 para ambos detectores obtidos nos equipamentos de raios X fixo (foco fino e foco grosso) e Raios X móvel.

\begin{tabular}{|c|c|c|c|c|c|c|c|c|c|c|}
\hline \multirow{3}{*}{ Equip. } & \multicolumn{5}{|c|}{ Cobia Smart } & \multicolumn{5}{|c|}{ UNFORS } \\
\hline & \multicolumn{3}{|c|}{$(\mathrm{CSR} \pm \Delta \mathrm{CSR}) \mathrm{mm} \mathrm{Al}$} & \multicolumn{2}{|c|}{$\mathrm{VP}(\%)$} & \multicolumn{3}{|c|}{$(\mathrm{CSR} \pm \Delta \mathrm{CSR}) \mathrm{mm} \mathrm{Al}$} & \multicolumn{2}{|c|}{ VP (\%) } \\
\hline & M1 & M2 & M3 & $\begin{array}{c}\text { M1\& } \\
\text { M2 }\end{array}$ & $\begin{array}{c}\text { M1\& } \\
\text { M3 }\end{array}$ & M1 & M2 & M3 & $\begin{array}{c}\text { M1\& } \\
\text { M2 }\end{array}$ & $\begin{array}{c}\text { M1\& } \\
\text { M3 }\end{array}$ \\
\hline $\begin{array}{c}\text { RX-F } \\
\text { FF }\end{array}$ & $3,0 \pm 0,7$ & $3,1 \pm 0,3$ & $3,1 \pm 0,3$ & 3,3 & 3,3 & $3,0 \pm 0,7$ & $3,1 \pm 0,2$ & $3,1 \pm 0,3$ & 3,3 & 3,3 \\
\hline $\begin{array}{c}\text { RX-F } \\
\text { FG }\end{array}$ & $3,0 \pm 0,7$ & $3,1 \pm 0,3$ & $3,1 \pm 0,3$ & 3,3 & 3,3 & $2,9 \pm 0,6$ & $3,0 \pm 0,2$ & $3,0 \pm 0,3$ & 3,4 & 3,4 \\
\hline $\begin{array}{c}\text { RX-M } \\
1\end{array}$ & $3,0 \pm 0,7$ & $3,1 \pm 0,3$ & $3,1 \pm 0,3$ & 3,3 & 3,3 & $3,0 \pm 0,7$ & $3,0 \pm 0,2$ & $3,0 \pm 0,3$ & 0,0 & 0,0 \\
\hline $\begin{array}{c}\text { RX-M } \\
2\end{array}$ & $2,9 \pm 0,7$ & $3,0 \pm 0,3$ & $3,1 \pm 0,3$ & 3,4 & 6,9 & $2,9 \pm 0,7$ & $3,0 \pm 0,2$ & $3,0 \pm 0,3$ & 3,4 & 3,4 \\
\hline
\end{tabular}

É possível observar através do teste de hipóteses t-student não pareado (valor P de dupla calda de maior divergência $=0,7765, \mathrm{k}=2$ ) que os métodos $\mathrm{M} 1$ e M2 para os três equipamentos de raios $\mathrm{X}$ utilizados possuem resultados estatisticamente iguais considerando a precisão de cada método. É observada uma variação percentual máxima de 6,9\% entre os resultados absolutos das CSR obtidas por M1 e M3 para o segundo equipamento de raios X móvel utilizando o Cobia Smart. Para o UNFORS a mesma relação máxima foi de 3,4\%. Ainda assim, em ambos os casos o mesmo teste de hipóteses considerou a divergência insignificante com $\mathrm{P}=0,9094, \mathrm{k}=2$. 
Apesar da variação percentual superior a 5,0\%, esses resultados são considerados equivalentes, e assim, o uso de M1, M2 ou M3 para estimativa de CSR não apresentam diferença estatística na avaliação final, contudo, M2 e M3 apresentam relevante ganho na precisão por apresentarem erro padrão até 3,5 vezes menores. Diante da convergência dos resultados encontrada para o valor central das medições, é possível apontar que todos os métodos apresentaram uma exatidão confiável, entretanto, o método com pior precisão (M1) indica que poderá apresentar oscilação significativa quando variados os filtros de $\mathrm{Al}$ (maior fonte de incerteza do método, $5 \%$ ), diminuindo a potencial confiabilidade do resultado deste método. O erro padrão de M1 é muito permissivo, levando o resultado da comparação à uma baixa confiabilidade.

Na tabela 4 VP M1\&M2 é a variação percentual de M2 com respeito a M1, VP M1\&M3 é a variação percentual de M3 com respeito a M1 dos equipamentos de RXF, RXM e MM nas qualidades de feixe de $80 \mathrm{kVp}$ para RXF e RXM, e $28 \mathrm{kVp}$ para MM.

Tabela 4: Resultado de CSR medidas com a CI Radcal para metodologia M1 e M2, e NOMEX para as três metodologias (M1, M2 e M3) e variação percentual entre as metodologias M1 \& M2 para ambos detectores e M1 \& M3 para NOMEX, obtidos nos equipamentos de raios X fixo (foco fino e foco grosso), raios X móvel, mamógrafo e tomossíntese.

\begin{tabular}{|c|c|c|c|c|c|c|c|c|c|}
\hline \multirow{4}{*}{ Equip } & \multirow{4}{*}{ kV/alvo/filtro } & \multicolumn{8}{|c|}{$(\mathrm{CSR} \pm \Delta \mathrm{CSR}) \mathrm{mm} \mathrm{Al}$} \\
\hline & & \multicolumn{2}{|c|}{ CI Radcal } & \multirow{2}{*}{\multicolumn{2}{|c|}{$\begin{array}{l}\mathrm{VP} \\
(\%) \\
\mathrm{M1}\end{array}$}} & \multicolumn{2}{|l|}{ NOMEX } & \multicolumn{2}{|c|}{ VP (\%) } \\
\hline & & \multirow[b]{2}{*}{ M1 } & \multirow[b]{2}{*}{ M2 } & & \multirow[b]{2}{*}{ M1 } & \multirow[b]{2}{*}{ M2 } & \multirow[b]{2}{*}{ M3 } & \multirow{2}{*}{$\begin{array}{c}\text { M1 } \\
\& \\
\text { M2 } \\
\end{array}$} & \multirow{2}{*}{$\begin{array}{c}\text { M1 } \\
\& \\
\text { M3 } \\
\end{array}$} \\
\hline & & & & $\begin{array}{c}\& \\
\text { M2 }\end{array}$ & & & & & \\
\hline $\begin{array}{c}\text { RX-F } \\
\text { FF }\end{array}$ & $80 / \mathrm{W} / \mathrm{Al}$ & $3,2 \pm 0,6$ & $3,2 \pm 0,3$ & 0,0 & $3,1 \pm 0,5$ & $3,1 \pm 0,3$ & $3,1 \pm 0,3$ & 0,0 & 0,0 \\
\hline $\begin{array}{c}\text { RX-F } \\
\text { FG }\end{array}$ & $80 / \mathrm{W} / \mathrm{Al}$ & $3,1 \pm 0,6$ & $3,2 \pm 0,3$ & 3,2 & $3,0 \pm 0,5$ & $3,0 \pm 0,3$ & $3,0 \pm 0,3$ & 0,0 & 0,0 \\
\hline $\begin{array}{c}\text { RX-M } \\
1\end{array}$ & $80 / \mathrm{W} / \mathrm{Al}$ & $3,1 \pm 0,6$ & $3,2 \pm 0,3$ & 3,2 & $3,0 \pm 0,5$ & $3,1 \pm 0,3$ & $3,0 \pm 0,3$ & 3,3 & 0,0 \\
\hline $\begin{array}{c}\text { RX-M } \\
2\end{array}$ & $80 / \mathrm{W} / \mathrm{Al}$ & $3,0 \pm 0,6$ & $3,1 \pm 0,3$ & 3,3 & $2,9 \pm 0,5$ & $3,0 \pm 0,3$ & $3,0 \pm 0,3$ & 3,4 & 3,4 \\
\hline \multirow{2}{*}{ MM-1 } & $28 / \mathrm{Mo} / \mathrm{Rh}$ & $0,35 \pm 0,06$ & $0,37 \pm 0,03$ & 5,7 & $0,34 \pm 0,04$ & $0,36 \pm 0,02$ & $0,33 \pm 0,01$ & 5,9 & 2,9 \\
\hline & 28/Mo/Mo & $0,39 \pm 0,07$ & $0,41 \pm 0,04$ & 5,1 & $0,38 \pm 0,05$ & $0,40 \pm 0,03$ & $0,38 \pm 0,01$ & 5,3 & 0,0 \\
\hline \multirow{2}{*}{ MM-2 } & 28/W/Rh & $0,45 \pm 0,08$ & $0,48 \pm 0,05$ & 6,7 & $0,47 \pm 0,06$ & $0,49 \pm 0,03$ & $0,52 \pm 0,01$ & 4,2 & 10,6 \\
\hline & 28/W/Ag & $0,54 \pm 0,08$ & $0,55 \pm 0,05$ & 1,8 & $0,54 \pm 0,08$ & $0,55 \pm 0,03$ & $0,53 \pm 0,01$ & 1,8 & 1,8 \\
\hline
\end{tabular}


$\mathrm{Na}$ tabela 4, analisando os mesmos equipamentos de raios $\mathrm{X}$ convencional apresentados na tabela 3, observamos que a maior variação percentual entre os valores absolutos $(3,4 \%)$ ocorreu quando utilizamos o detector NOMEX ao compararmos os resultados obtidos para M2 em relação à M1 e, M3 em relação à M1. Igualmente ao caso apresentado na tabela 3, apesar da variação percentual, os resultados são considerados estatisticamente equivalentes quando são analisados através do teste de hipóteses t-student não pareado (valor $\mathrm{P}$ de dupla calda de maior divergência $=$ 0,9186, k=2), então, o uso de M1 ou M2 para CI e M1, M2 ou M3 para NOMEX não produz diferenças significativas nos resultados da avaliação da CSR. Logo é aceitável aplicar qualquer um dos três métodos para estimativa da CSR em equipamentos de raios $\mathrm{X}$, entretanto, o tamanho do erro padrão inerente ao método M1 apresenta valores até 2 vezes maiores que os encontrados nos demais métodos M2 e M3. O erro padrão de M1 novamente se mostrou muito permissivo, levando a resultados com baixa confiabilidade.

Na avaliação da mamografia, M2 e M1 apresentaram a maior variação percentual entre os resultados absolutos $(6,7 \%)$ quando avaliado o mamógrafo com alvo de tungstênio (W) e filtro de ródio $(\mathrm{Rh}$ ) utilizando $\mathrm{CI}$. $\mathrm{O}$ mesmo teste apresentou $\mathrm{P}=0,8904, \mathrm{k}=2$, levando à interpretação de que são estatisticamente iguais. Para esse mesmo equipamento foi observada uma variação percentual de $10,6 \%$ entre M1 e M3 quando avaliado pelo NOMEX, com $\mathrm{P}=0,7227, \mathrm{k}=2$, também estatisticamente iguais. Apesar das variações percentuais elevadas, esses resultados são considerados equivalentes, e novamente M1 ou M2, utilizando CI, e M1, M2 ou M3 utilizando o NOMEX podem ser usados para estimativa da CSR em equipamentos de mamografia, entretanto, os valores das incertezas são até 8 vezes menores no M3. Atribuímos à esse maior VP para a combinação $\mathrm{W} / \mathrm{Rh}$ as condições de contorno aplicadas ao modelo matemático adotado pelo equipamento NOMEX, não é possível identificar em qual parâmetro exatamente. É possível que o NOMEX tenha tido sua calibração inicial em uma versão mais inicial do mamógrafo e que não tenha acompanhado as atualizações naturais que estes equipamentos sofrem, podendo levar a modificação de algum parâmetro das condições de contorno iniciais, como por exemplo o ângulo do alvo. Outra possibilidade é que embora marca e modelo sejam os mesmos, tubos de raios X podem ser vendidos separadamente, sendo possível a escolha da marca do tubo, consequentemente, diversas condições de contorno e calibração inicial da FT. O teste de hipótese não é por si só a melhor maneira de avaliar a confiabilidade dos resultados, visto que são significativamente iguais 
em decorrência do elevado erro padrão do método M1, que possuí em sua composição de incertezas a espessura do filtro de alumínio como a componente mais representativa. A divergência próxima de $10 \%$ é crítica, pois tem impacto direto nos critérios de aceitabilidade. Por outro lado, o método M3 possui fragilidades com relação a calibração inicial e possibilidades de upgrades dos equipamentos.

Com objetivo de comparar os resultados obtidos pelos métodos M1, M2 e M3 e obter uma diferenciação estatística, considerando as incertezas associadas aos resultados individuais de cada método, os valores obtidos pelo M1 são amplamente permissivos, visto que os grandes valores da incerteza ampliam o espectro da aceitabilidade comparativa em aproximadamente $35,6 \%$ do seu valor absoluto ao compará-lo com o valor de outro resultado obtido a partir de outro método. O M2 reduz o range de aceitabilidade ao nível de aproximadamente $20,8 \%$, entretanto o M3 apresenta um range de incerteza menor que 6,1\% refletindo um ganho relevante à precisão da medição. É sugestivo que os resultados obtidos pelos métodos M1 e M2 sejam comparados à limites de tolerâncias mais rigorosos (definido pela nova RDC 330 Instrução Normativa $\mathrm{N}^{\circ} 52$ e $\mathrm{N}^{\circ} 54$, como: CSR >2,6 mm Al para RX, 0,31 $\leq \mathrm{CSR} \leq 0,40 \mathrm{~mm} \mathrm{Al} \mathrm{para} \mathrm{MM} \mathrm{com} \mathrm{combinação} \mathrm{alvo/filtro} \mathrm{Mo/Mo} \mathrm{e}$ $0,31 \leq \mathrm{CSR} \leq 0,47 \mathrm{~mm}$ Al para combinação alvo/filtro $\mathrm{Mo} / \mathrm{Rh}$ ), visto que sua elevada incerteza concede uma elevada chance de conclusão equivocada por motivo de erros sistemáticos.

As Figuras 3 e 4 apresentam em forma gráfica, os dados das Tabelas 3 e 4 . A Figura 3 apresenta um gráfico da estimativa de CSR pelos três métodos (M1, M2 e M3) para o equipamento de raios X convencional fixo, operado em modo foco fino (FF) e foco grosso (FG) e os equipamentos de raios X convencional móvel de foco único (UNI1 e UNI2), conforme relação na tabela 1, avaliado pelos quatro detectores, Câmara de Ionização (CI), NOMEX (N), Cobia Smart (CS) e Unsfors (U), e a Figura 4 apresenta um gráfico dos resultados das CSR obtidas pelos três métodos (M1, M2 e M3) para os dois mamógrafos. Os equipamentos de mamografia foram avaliados utilizando a CI e o NOMEX. 


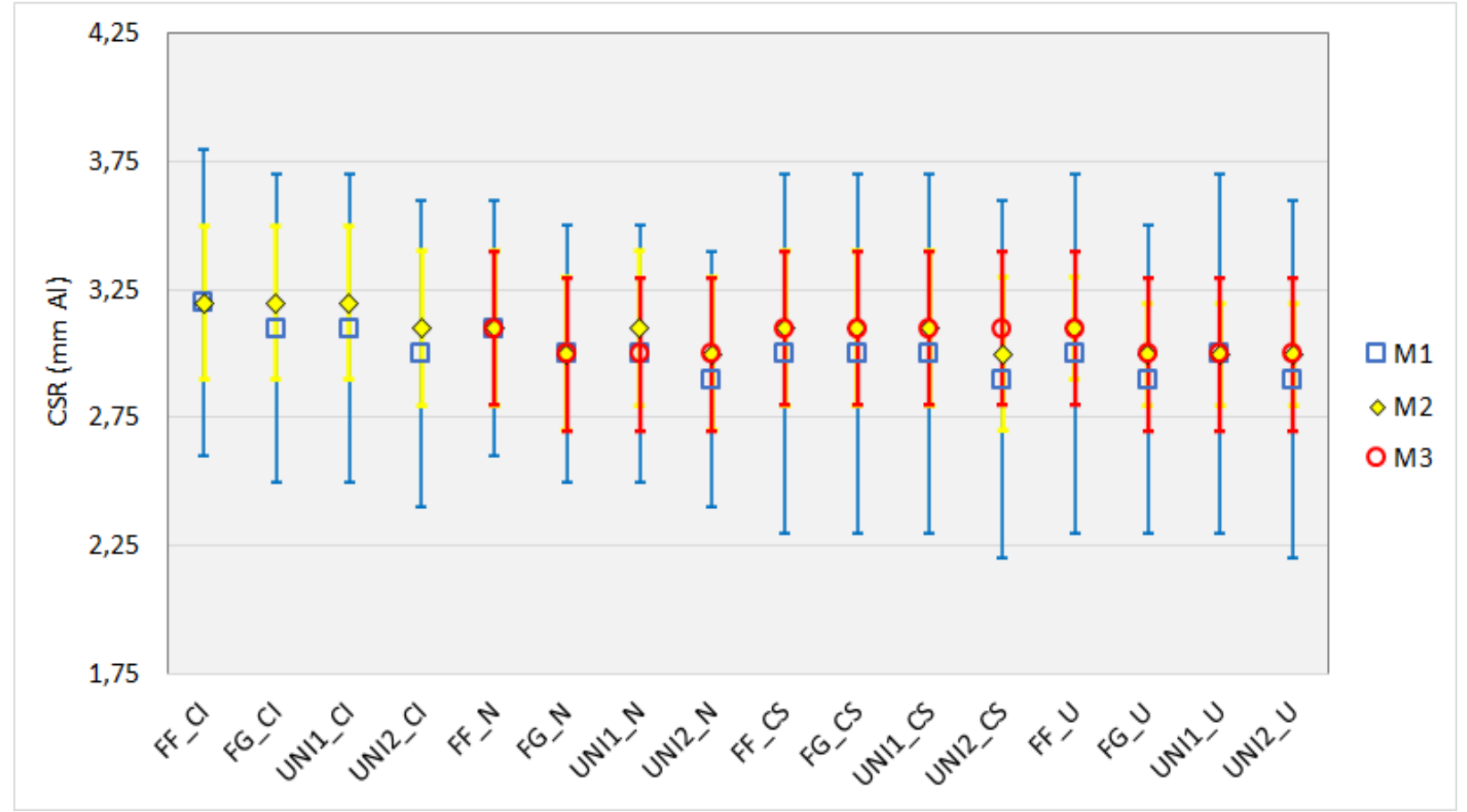

Figura 3: Comparação de CSR estimado por M1, M2 e M3 utilizando Câmara de Ionização (CI), NOMEX (N), Cobia Smart (CS) e Unsfors $(U)$, para equipamentos de raios $X$ fixo $(R X-F)$ operado em foco fino ( $F F)$ e foco grosso $(F G)$ e equipamentos de raios $X$ móvel ( $R X-M)$.

Legenda: FF = Foco Fino; FG = Foco Grosso; UNI1 = Foco Único $($ Móvel 1); UNI2 = Foco Único (Móvel 2) CI = Câmara de Ionização; N = NOMEX; CS = Cobia Smart; U = UNFORS. 


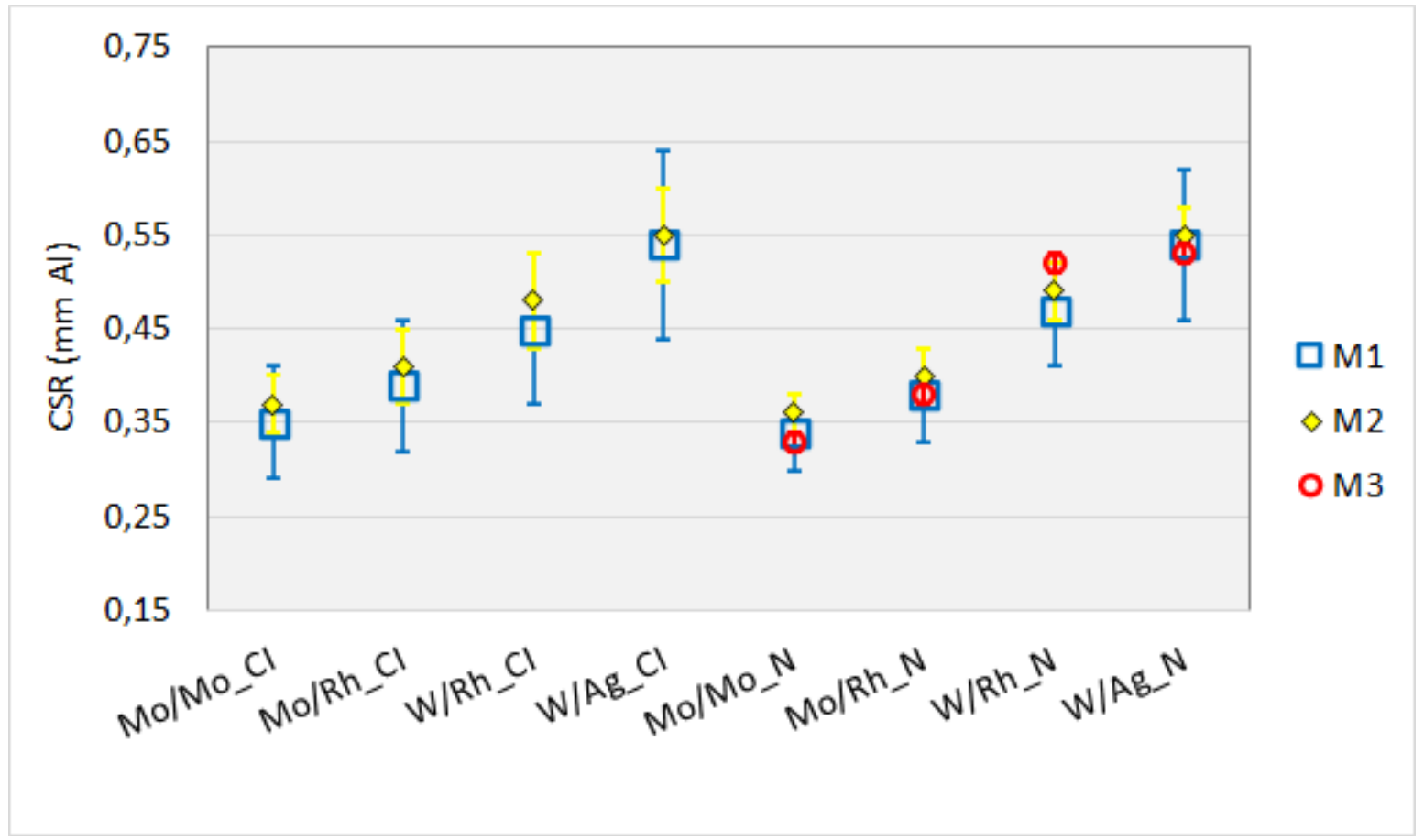

Figura 4: Comparação de CSR estimado por M1, M2 e M3 utilizando Câmara de Ionização (CI) e NOMEX (N), para equipamentos de mamografia (MM) com alvo de tungstênio, filtro de ródio ou prata, e MM com alvo de molibdênio, filtro molibdênio ou ródio.

Legenda: $\mathrm{Mo} / \mathrm{Mo}=$ Molibdênio/Molibdênio; $\mathrm{Mo} / \mathrm{Rh}=$ Molibdênio/Ródio; $\mathrm{W} / \mathrm{Rh}=$ Tungstênio/Ródio; W/Ag = Tungstênio/Prata. CI = Câmara de Ionização; N = NOMEX.

Podemos observar na Figura 3 que independentemente do tipo do detector, a CSR estimada por M1 apresenta uma incerteza associada maior que as demais. Em alguns casos essa incerteza representa 48,3\% do valor absoluto do resultado. Para mamografia, Figura 4, essa incerteza atinge 35,6\%. Logo, o uso de M1 para estimar CSR na mamografia não entrega garantias de que a precisão do resultado é confiável, pois permite uma elevada dispersão, embora neste conjunto de medições a exatidão tenha sido satisfatória. Hipoteticamente, o fabricante garante que as placas de $\mathrm{Al}$ 99\% ultrapuro possuem a espessura nominal precisas em até 5\%, fazendo com essa seja a fonte de incerteza mais relevante de toda a medição pelo M1, neste diapasão no caso de variações aleatórias do uso dessas placas para reprodução deste teste, poderia levar à variações relevantes na exatidão resultante da avaliação da CSR, trazendo insegurança ao método. É possível que com o auxílio de 
um paquímetro calibrado seja conferida as espessuras nominais e redimensionada a fonte de incerteza para que este problema seja minimizado.

A tomada de decisão a partir dos resultados de uma avaliação imprecisa da CSR pode trazer consequências importantes como a interdição temporária do equipamento [16], portanto é conveniente que os métodos com alta possibilidade de indução de falso positivo ou falso negativo sejam evitados, ou utilizados sob maior rigor, por exemplo, com a aplicação de um fator de segurança proporcional à metade da barra de incerteza sobre o limite de tolerância, tornando-o mais restritivo e consequentemente menos sensível à influência de uma medição decorrente de um método com alta dispersão intrínseca.

Para comparar os resultados da CSR estimada por M1 em relação ao estimado por M3 para detectores distintos, adotamos o protocolo nacional ANVISA [16] e referências internacionalmente reconhecidas [16-23]. Na maioria destas referências, a estimativa da CSR deve ser obtida por M1 utilizando uma CI. A Tabela 5 apresenta o comparativo dos valores de CSR obtidos por M1 utilizando CI e M3 a partir dos três detectores de estado sólido. Na tabela, VP M1\&M3 é a variação percentual de M3 com relação a M1 dos equipamentos de RX-F, RX-M e MM nas qualidades de feixe de $80 \mathrm{kV}$ para RX-F e RX-M e $28 \mathrm{kV}$ para MM.

Tabela 5: Resultado de CSR medidas com o Cobia Smart, UNFORS e NOMEX para a metodologia M3 e CSR medidas com a CI Radcal pela metodologia M1, e variação percentual entre as metodologias M1 \& M3 para os três detectores, avaliados nos equipamentos de raios X fixo (foco fino e foco grosso) e raios X móvel, mamógrafo e tomossíntese.

\begin{tabular}{ccccccccc}
\hline & & \multicolumn{7}{c}{ (CSR $\pm \Delta$ CSR) $\mathbf{m m ~ A l}$} \\
\cline { 3 - 8 } Equip & kV/alvo/filtro & CI Radcal & NOMEX & VP(\%) & Cobia & VP (\%) & UNFORS & VP (\%) \\
\cline { 3 - 9 } & & M1 & M3 & $\begin{array}{c}\text { M1\& } \\
\text { M3 }\end{array}$ & M3 & $\begin{array}{c}\text { M1\& } \\
\text { M3 }\end{array}$ & M3 & $\begin{array}{c}\text { M1\& } \\
\text { M3 }\end{array}$ \\
\hline RX-F FF & 80/W/Al & $3,2 \pm 0,6$ & $3,1 \pm 0,3$ & 3,1 & $3,1 \pm 0,3$ & 3,1 & $3,1 \pm 0,3$ & 3,1 \\
RX-F FG & 80/W/Al & $3,1 \pm 0,6$ & $3,0 \pm 0,3$ & 3,2 & $3,1 \pm 0,3$ & 0,0 & $3,0 \pm 0,3$ & 3,2 \\
RX-M 1 & 80/W/Al & $3,1 \pm 0,6$ & $3,0 \pm 0,3$ & 3,2 & $3,1 \pm 0,3$ & 0,0 & $3,0 \pm 0,3$ & 3,2 \\
RX-M 2 & 80/W/Al & $3,0 \pm 0,6$ & $3,0 \pm 0,3$ & 0,0 & $3,1 \pm 0,3$ & 3,3 & $3,0 \pm 0,3$ & 0,0 \\
MM-1 & 28/Mo/Rh & $0,35 \pm 0,06$ & $0,33 \pm 0,01$ & 5,7 & - & - & - & - \\
& 28/Mo/Mo & $0,39 \pm 0,07$ & $0,38 \pm 0,01$ & 2,6 & - & - & - & - \\
MM-2 & 28/W/Rh & $0,45 \pm 0,08$ & $0,52 \pm 0,01$ & 15,6 & - & - & - & - \\
& 28/W/Ag & $0,54 \pm 0,08$ & $0,53 \pm 0,01$ & 1,8 & - & - & - & - \\
\hline
\end{tabular}


A variação percentual da CSR estimada por M1 pela câmara de ionização e M3 pelo NOMEX para equipamentos de raios $\mathrm{X}$ convencionais não ultrapassa 3,2\%. Quando ambos os métodos M1 e M3 foram realizados exclusivamente pelo Cobia Smart neste mesmo equipamento de raios X, apresentados na tabela 3, a divergência foi de 6,9\%. Embora a estimava da CSR possa ser realizada por qualquer detector e qualquer método, a elevada incerteza do M1 aponta pelo maior rigor sobre a análise dos seus resultados. A partir dos resultados deste trabalho é recomendado que seja aplicada uma margem de segurança de $20 \%$ (metade da magnitude da barra de incerteza aproximada) sobre os limites de tolerância para torná-lo um método seguro, então, por exemplo, ao realizar as medições em raios $\mathrm{X}$ convencional com a técnica de tensão de $80 \mathrm{kVp}$, ao invés de considerar os limites de tolerância da literatura [16] de 2,3 mm Al para monofásico e 2,6 mm Al para trifásico, aplica-se o fator de segurança de $20 \%$, elevando-os para 2,8 e 3,1 $\mathrm{mm} \mathrm{Al}$, respectivamente. Sob o mesmo raciocínio, para o M2 é possível sugerir uma margem de segurança de 10\%, encontrando 2,5 e $2,9 \mathrm{~mm} \mathrm{Al}$, respectivamente.

A variação percentual da CSR estimada por M1 (câmara de ionização) e M3 (NOMEX) para equipamentos de mamografia alcançou 15,6\%, sendo superior aos 10,6\% observados nos resultados apresentados na tabela 4 NOMEX/NOMEX. Apesar da elevada variação percentual, os resultados de CSR são considerados estatisticamente equivalentes pelo teste de hipóteses apropriado. As maiores variações percentuais entre os valores absolutos estão relacionadas as próprias características do conjunto alvo/filtro, que possui filtro de elemento diferente do alumínio (Al 99\%) utilizado como atenuador para a medição da CSR. Com isso, a forma do espectro de transmissão é alterada a cada lâmina incrementada, inclusive alterando o valor da tensão medida percebida no caso das medições realizadas pelos medidores multiparâmetro (NOMEX). Nos raios X convencionais, o espectro de transmissão é deslocado em direção a faixa de energia mais alta, entretanto esse fenômeno na faixa de filtração analisada não leva a mudanças significativas nos valores de tensão apresentadas nos medidores multiparâmetros.

O medidor de radiação Cobia Smart foi calibrado em relação ao valor de CSR em laboratório com rastreabilidade certificada. Com a aplicação dos fatores de correção, a CSR obtida pelo Cobia Smart por M3 foi considerada nesse trabalho como o "valor verdadeiro". Sendo assim, os demais resultados foram comparados a ele quanto a exatidão. A tabela 6 apresenta a comparação entre CSR 
estimada por M3 utilizando o Cobia Smart e a CSR obtida pelo UNFORS para M1, M2 e M3, Câmara de Ionização M1 e M2 e NOMEX para M1, M2 e M3. As fontes de radiação foram, o equipamento de raios $\mathrm{X}$ fixo operado em modo foco fino e foco grosso e o equipamento de raios $\mathrm{X}$ móvel.

Tabela 6: Relação do desvio da exatidão (\%) entre o 'valor verdadeiro’ (M3 Cobia Smart), M1 e M2, e as estimativas de CSR pelas metodologias M1, M2 e M3 por UNFORS e NOMEX, e M1 e $\mathrm{M} 2$ pela CI Radcal, avaliada nos equipamentos de raios $\mathrm{X}$ fixo (foco grosso e foco fino) e raios $\mathrm{X}$ móveis.

\begin{tabular}{|c|c|c|c|c|c|c|c|c|c|c|c|c|}
\hline \multirow{3}{*}{ Equip. } & \multirow{3}{*}{$\begin{array}{c}\text { kV/alvo } \\
\text { /filtro }\end{array}$} & $\begin{array}{c}\text { Valor } \\
\text { Verdadeiro }\end{array}$ & \multicolumn{10}{|c|}{ Desvio da Exatidão (\%) } \\
\hline & & \multicolumn{3}{|c|}{ Cobia Smart } & \multicolumn{3}{|c|}{ UNFORS } & \multicolumn{2}{|c|}{$\begin{array}{c}\text { CI } \\
\text { Radcal }\end{array}$} & \multicolumn{3}{|c|}{ NOMEX } \\
\hline & & M3 & M1 & M2 & M1 & M2 & M3 & M1 & M2 & M1 & M2 & M3 \\
\hline RX-F FF & $80 / \mathrm{W} / \mathrm{Al}$ & $3,1 \pm 0,3$ & 3,2 & 0,0 & 3,2 & 0,0 & 0,0 & 3,2 & 3,2 & 0,0 & 0,0 & 0,0 \\
\hline RX-F FG & $80 / \mathrm{W} / \mathrm{Al}$ & $3,1 \pm 0,3$ & 3,2 & 0,0 & 6,5 & 3,2 & 3,2 & 0,0 & 3,2 & 3,2 & 3,2 & 3,2 \\
\hline RX-M 1 & 80/W/Al & $3,1 \pm 0,3$ & 3,2 & 0,0 & 3,2 & 3,2 & 3,2 & 0,0 & 3,2 & 3,2 & 0,0 & 3,2 \\
\hline RX-M 2 & $80 / \mathrm{W} / \mathrm{Al}$ & $3,1 \pm 0,3$ & 6,5 & 3,2 & 6,5 & 3,2 & 3,2 & 3,2 & 0,0 & 6,5 & 3,2 & 3,2 \\
\hline
\end{tabular}

$\mathrm{O}$ desvio da exatidão para equipamentos de raios $\mathrm{X}$ convencionais não ultrapassa 6,5\%, observadas para M1 nos detectores Cobia Smart, Unfors e NOMEX, sendo inferior ao intervalo de aceitabilidade de 48,3\%, como esperado, já que todos os resultados de estimativa de CSR se apresentam estatisticamente iguais. Para o M2 e M3 a aceitabilidade é de até 20,8\%, com desvio da exatidão apresentando valores de até 3,2\%.

A instrumentação de referência usada para calibração do Cobia Smart no laboratório foi um NOMEX fabricado pela PTW Freiburg, Modelo T11049 com rastreabilidade PTW 1313709. Para a mamografia, o NOMEX foi utilizado e o valor obtido por M3 foi considerado o "valor verdadeiro" da CSR.

A Tabela 7 apresenta a relação do desvio da exatidão utilizando como valor "verdadeiro" o resultado da CSR estimada por M3 com relação a CSR estimada por M1 e M2 por NOMEX e M1 e M2 por Câmara de Ionização. As fontes de radiação foram os dois equipamentos de mamografia. 
Tabela 7: Relação do desvio da exatidão (\%) entre o ‘valor verdadeiro' (M3 NOMEX), M1 e M2, e as estimativas de CSR pelas metodologias M1 e M2 pela CI Radcal, avaliada nos mamógrafos e suas respectivas combinação kV/alvo/filtro.

\begin{tabular}{|c|c|c|c|c|c|c|}
\hline \multirow{3}{*}{ Equip. } & \multirow{3}{*}{ kV/alvo/filtro } & $\begin{array}{c}\text { Valor } \\
\text { Verdadeiro } \\
(\mathrm{CSR} \pm \Delta \mathrm{CSR}\end{array}$ & \multicolumn{4}{|c|}{ Desvio da Exatidão (\%) } \\
\hline & & \multicolumn{3}{|c|}{ NOMEX } & \multicolumn{2}{|c|}{ CI Radcal } \\
\hline & & M3 & M1 & M2 & M1 & M2 \\
\hline \multirow{2}{*}{ MM-1 } & 28/Mo/Rh & $0,33 \pm 0,01$ & 3,0 & 9,1 & 6,1 & 12,1 \\
\hline & 28/Mo/Mo & $0,38 \pm 0,01$ & 0,0 & 5,3 & 2,6 & 7,9 \\
\hline \multirow{2}{*}{ MM-2 } & 28/W/Rh & $0,52 \pm 0,01$ & 9,6 & 5,8 & 13,5 & 7,7 \\
\hline & 28/W/Ag & $0,53 \pm 0,01$ & 1,9 & 3,8 & 1,9 & 3,8 \\
\hline
\end{tabular}

O desvio da exatidão para equipamentos de mamografia não ultrapassa 13,5\%, observadas para M1 na Câmara de Ionização, sendo inferior ao intervalo de aceitabilidade de 35,6\%. Para M2, a maior desvio foi de $12,1 \%$ observado na Câmara de Ionização para a mamografia com combinação alvo/filtro Mo/Mo.

O valor da CSR que cada fonte de raios X deve obedecer é definido em protocolos nacionais [16] e internacionais [13-21]. Dentre os protocolos mais aceitos, o mais flexível [21] define para raios $\mathrm{X}$ convencional valores de CSR que apresentam uma faixa de aceitabilidade de $16,7 \%$. Para mamografia essa faixa de aceitabilidade é de até 13,5\% para combinação alvo/filtro (Mo/Mo). Uma faixa de aceitabilidade de 63,7\% é encontrada para combinação alvo/filtro (W/Ag).

O guia europeu para garantia de qualidade em câncer de mama [17], se preocupa em definir faixa de aceitabilidade de CSR mais rigorosas. Para esse protocolo, a faixa de aceitabilidade é de até $5,5 \%$ para combinação alvo/filtro (Mo/Mo). Para esse protocolo especificamente, seria mais adequado a utilização de métodos mais precisos, como M3, desde que tivéssemos garantias de que há baixa divergência entre M1/M2 e M3, garantindo minimamente concordância entre as condições de contorno adotadas no modelo matemático. Tomando por base o protocolo mais restritivo [17], podemos concluir que nenhum resultado de CSR ultrapassou os limites definidos nos documentos 
internacionais ou nacional. Mas caso tivéssemos um objeto de estudo (equipamento de raios $\mathrm{X}$ /mamógrafos) com CSR limítrofe, seria possível que os resultados entre os métodos nos levassem a decisões de aceitabilidade divergentes entre si.

A Tabela 8 foi obtida a partir da referência 14 e apresenta as fontes de incertezas mais relevantes na estimativa de CSR.

Tabela 8: Percentual de incerteza das fontes de incertezas mais relevantes na estimativa de CSR [14].

Fonte de Incerteza Incertezas $(\%)$

\begin{tabular}{ll}
\hline Repetibilidade da Medida (Desvio Padrão) & 0,80 \\
\hline Ajuste dos pontos sobre a curva de atenuação & 0,30 \\
\hline Tamanho do campo de irradiação & 0,20 \\
\hline Posicionamento da câmara de ionização e atenuadores & 0,10 \\
\hline Calibração dos dosímetros & 0,30 \\
\hline Resolução do instrumento & 0,01 \\
\hline Dependência energética da câmara de ionização & 1,10 \\
\hline Correção para temperatura e pressão & 0,30 \\
\hline Espessura de atenuadores & 1,10 \\
\hline Pureza dos atenuadores & 0,30 \\
\hline
\end{tabular}

Os valores de incerteza estimadas para CSR nesse trabalho são obtidos pela equação 2 para M1 e equação 4 para M2. Em ambas as equações, as incertezas utilizadas foram obtidas a partir das especificações do fabricante. Nesses casos, a incerteza da leitura do medidor para exposição na Câmara de Ionização é de 4,0\%, Cobia Smart e Unfors 5,0\% e NOMEX é de 3,5\% para RX-F e RX-M e 2,5\% para MM. Além disso, a incerteza na espessura dos atenuadores é de 5,0\%. Essas incertezas são uma ordem de grandeza superiores a 80,0\% das fontes de incertezas apresentadas na Tabela 8.

Em clinicas ou hospitais em que não há disponibilidade de um detector do estado sólido para realizar a medição da CSR pelo M3, ou que o detector não tenha a tecnologia de cálculo automático, como sugestão, é possível que avaliem a segunda CSR quando forem avaliar um mamógrafo, visto que para atingir a segunda CSR é necessária a introdução de maiores espessuras de lâminas de alumínio sob o feixe, naturalmente o espectro de transmissão atingirá um padrão mais 
estável com características de maior influência do alumínio (último material de interação) e menos do alvo/filtro utilizado pelo mamógrafo. Desta forma, apresentará menores discrepâncias entre os espectros medidos antes e depois da segunda CSR, ao contrário do que ocorre para as espessuras próximas da primeira CSR. É possível verificar essa constatação utilizando um detector multiparâmetro através da observação da variação no valor da tensão em função da inserção dos filtros de $\mathrm{Al}$ que em decorrência da alteração abrupta do espectro a cada inserção do filtro de $\mathrm{Al}$, a tensão média varia mais para menores espessuras de filtros de Al.

Uma alternativa se baseia no ajuste a partir das 4 medições mais próximas da CSR. Após o ajuste exponencial simples com auxílio de um software gráfico, a CSR pode ser obtida pela equação 3, entretanto, ao invés de usar o parâmetro "a" (valor de exposição sem material atenuador), usamos o parâmetro "a" (constante obtida pelo ajuste da curva), de forma que a nova CSR depende apenas de $\mathrm{R}_{0}$, que é a constante de decaimento. Apesar de menos preciso que o resultado obtido para o caso de ajuste de 10 pontos, o uso dos 4 pontos resultaria em um valor de CSR mais fidedigno, pois eliminaria a influência de pontos distantes, obtidos a partir da região de espectros mais alterados devido a adição e influência das placas de alumínio. Uma vantagem relevante desse método é a eliminação da medição inicial sem filtro, onde a característica do espectro é totalmente distinta daquela medida com a adição de filtros de alumínio. Em ambas sugestões, os limites atuais de CSR deverão ser atualizados. Nos equipamentos de raios X convencionais essa discussão não se repete, pois o espectro já é característico do alumínio, além de ser predominantemente decorrente de interações de Bremsstrahlung.

\section{CONCLUSÕES}

Os resultados apresentados nesse trabalho mostram que a estimativa da CSR apresenta variações percentuais não significativas quando avaliadas pelos três métodos (M1, M2 e M3) independentemente do tipo de equipamentos (NOMEX, Câmara de Ionização, Cobia Smart e Unsfors), desde que a combinação alvo/filtro da fonte de radiação seja W/Al. Essa combinação alvo/filtro é comum para raios $\mathrm{X}$ fixos, móveis e odontológicos. 
Para combinação alvo/filtro diferente de W/Al, as variações percentuais da exatidão, até 13,5\%, e da precisão entre os métodos, até 15,6\% entre M1 e M3, podem influenciar no resultado da avaliação da CSR de forma considerável, inclusive podendo alterar a conclusão de avaliação quando comparados com os limites de tolerância normativos.

Essas variações observadas em mamografia podem estar relacionadas a alteração da forma do espectro de transmissão após a adição de placas de alumínio ultrapuro no feixe, que é previamente filtrado por material diferente do alumínio. Assim, para evitar esse problema, o método para avaliação da CSR em mamógrafo mais adequado é o uso de um detector de radiação do estado sólido que tenha um modelo matemático de medição da CSR. É importante que esse parâmetro tenha rastreabilidade certificada para cada combinação alvo/filtro, ou que minimamente seja feito uma comparação entre os métodos M1 e M3 para certificar que as condições de contorno do modelo matemático adotado no software estão com consonância com o equipamento fonte sob avaliação.

No caso dos raios $\mathrm{X}$ convencional o M1 se mostrou impreciso, com incertezas chegando a 48,3\% do valor absoluto da CSR, tornando M3 mais adequado também na avaliação desse parâmetro nesse equipamento, embora tenham apresentado exatidão equivalentes. 


\section{AGRADECIMENTOS}

Gostaria de deixar o meu profundo agradecimento ao Instituto Nacional de Câncer José Alencar Gomes da Silva (INCA), e aos profissionais dessa instituição que direta ou indiretamente contribuíram para o sucesso desse trabalho.

\section{REFERÊNCIAS}

[1] MCKETTY, M. H. The AAPM/RSNA physics tutorial for residents. X-ray attenuation. Radiogr. Rev. Publ. Radiol. Soc. N. Am.Inc 18, p. 151-63; quiz 149. 1998.

[2] BUSHBERG, Jerrold T.; BOONE, John M. The essential physics of medical imaging. Lippincott Williams \& Wilkins, 2011.

[3] BUSHONG, Stewart C. Radiologic science for technologists-E-book: physics, biology, and protection. Elsevier Health Sciences, 2013.

[4] ONUSIC, D. M., MOURA, S. P., CÔRTE, R. E. F., ALEXANDRE, A. C. and MÜHLEN, S. S. Um novo dispositivo eletrônico para medição de camada semi-redutora em feixes de raios $\mathrm{X}$ diagnósticos por exposição única. RevBrasEngBiomed. 23, p. 45 - 52. 2007.

[5] IAEA - International Atomic Energy Agency. Quality assurance programme for digital mammography. Human Health Serie Nº. 17. IAEA, Vienna, Austria. 2011.

[6] T. ULREY, C. An Experimental Investigation of the Energy in the Continuous X-Ray Spectra Of Certain Elements. vol 11. 1918.

[7] PTW USER MANUAL. User Manual: NOMEX Multimeter T11049 Firmware Version 1.1 or higher. 2012.

[8] RTI MANUAL BARRACUDA. ReferenceManual:Barracuda\&QABrowser. 2012.

[9] RTI ELECTRONICS AB. Cobia: Reference Manual. USA. 2015.

[10] RTI ELECTRONICS AB. Application Note: Measurements of Total Filtration and kV with the Barracuda and the Piranha. 2007.

[11] RTI APPLICATION NOTE: AN-033, W. H. Application Note: AN-033. Quick HVL versus Traditional HVL measurement with Piranha. 2013.

[12] TROUT, E., KELLEY, J. and FURNO, E. A study of the inherent filtration of diagnostic xray tubes. Radiology 66, p. 102-102. 1956. 
[13] NAGEL, H. D. Limitations in the determination of total filtration of X-ray tube assemblies. Phys. Med. Biol.33, p. 271-289. 1988.

[14] LACERDA, A. H. de, Marco Aurélio de Sousa, Silva, Teógenes Augusto da, Oliveira. Influência da metodologia de avaliação da camada semi-redutora em radiologia diagnóstica. Radiol. Bras. 40, p. 331-6. 2007.

[15] RTI ELECTRONICS AB. Application Note: Conversion tables between HVL and total filtration. 2010.

[16] BRASIL. Ministério da Saúde. Agência Nacional de Vigilância Sanitária. Radiodiagnóstico Médico: Desempenho de equipamentos e segurança, Brasília: Ministério da Saúde. (Série A. Normas e Manuais Técnicos), 2005.

[17] PERRY, N., BROEDERS, M., DE WOLF, C., TÖRNBERG, S., HOLLAND, R. and VON KARSA, L. European guidelines for quality assurance in breast cancer screening and diagnosis. EuropeanComission, Luxembourg. 2006.

[18] AAPM - American Association of Physicists in Medicine. Equipment requirements and quality control for mammography. AAPM report n. 29. 1990.

[19] WAGNER, L. K., ARCHER, B. R. and CERRA, F. On the measurement of half-value layer in film-screen mammography. Med. Phys. 17, p. 989-97. 1990.

[20] AAPM - American Association of Physicists in Medicine. Quality control in diagnostic radiology. Medical PhysicsPublishing, AAPM report $\mathbf{n}^{\circ}$ 74, USA. 2002.

[21] SVPRR - Sociedad Valenciana de Protección Radiológica y Radiofísica. Manual de procedimientos de control de calidaden radiodiagnóstico. Generalitat Valenciana, SVPRR. Valencia. 2002.

[22] IAEA - International Atomic Energy Agency. Control de CalidadenMamografía. IAEATECDOC-1517. 2006.

[23] SEFM-SEPR-SERAM - Servicio de Física Médica - Servicio de Protección Radiológica SociedadEspañola de Radiologia Médica. Protocolo español de control de calidaden radiodiagnóstico. SEFM-SEPR-SERAM. Senda Editorial, Madrid. 2012.

[24] TAUHATA, L., SAlATI, I., PRINZIO, R. D. AND PRINZIO, A. R. D. Radioproteção e dosimetria: fundamentos. Instituto De Radioproteção E Dosimetria E Comissão Nacional de Energia Nuclear - IRD E CNEN. Rio de Janeiro. 2014.

[25] BIPM; IEC; IFCC; ILAC; ISSO; IUPAC; IUPAP; OIML - GUM 2008. Avaliação de dados de medição - Guia para a expressão de incerteza de medição. JCGM 100: 2008. $1^{a}$ ed. Setembro/2008.

[26] RADCAL CORPORATION. Model 2026C Radiation Monitor Controller Manual. 2000.

[27] BRASIL. Resolução da Diretoria Colegiada (RDC) N 330 de 20 de dezembro de 2019. Diário Oficial da União. Ed. 249, Seção 1. 2019. 